\title{
RODENT MALARIA PARASITES : MOLECULAR KARYOTYPES CHARACTERIZE SPECIES, SUBSPECIES AND LINES
}

\author{
AHAMADA SAID.*, WERY M.*, HAMERS R.**
}

\section{Summary :}

The molecular karyotypes of the African murine malaria parasites $P$. berghei ( 3 strains, 2 lines) $P$. yoelii (2 strains) $P$. chabaudi ( 3 strains, 1 line) and $P$. vinckei (4 strains) have been studied using orthogonal field alternation gel electrophoresis (OFAGE). The genome of each species was resolved into 9 to 11 distinct chromosomal DNA bands molecules of varying intensities which seem to represent 14 chromosomes ranging in size from $600 \mathrm{~kb}$ to $3500 \mathrm{~kb}$. The position of certain chromosomes allowed the identification of a unique karyotype for each of the strains and lines under study. P. yoelii appears by criteria of chromosome size, chromosome numbers and localisation of DNA probes to differ considerably from the other three rodent malaria species. The chromosomal location of 5 DNA probes allowed the identification of corresponding chromosomes in rodent malaria parasites and the differentiation between species and strains. Assignment of the "PMMSA" gene of P. c. chabaudi IP-PC I enables the distinction of the four rodent malaria species. The molecular karyotype combined to chromosomal assignment of DNA probes provides a useful tool for a more precise characterization by a genetic definition of malaria parasites.

KEY WORDS : Rodent plasmodium. species, strains. lines. clones, karyotype PFGE. DNA probes.

ABBREVIATIONS : PMMSA, precursor to the major merozoilte surface antigens; OFAGE, orthogonal field alternation gradient electrophoresis; PFGE. pulse field gradient electrophoresis.

\section{INTRODUCTION}

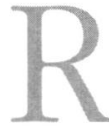

odent malaria parasites are useful laboratory models for human malaria research. The development of the malaria parasite varies with the parasite species and strain within one given host. The classification of species and subspecies of Plasmodium has classically been based on morphological and physiological characters. Biochemical characters were added during the last two decades or so (Carter, 1973 ; Walliker et al., 1987). Classical cytogenetic studies are difficult to carry out with malaria parasites because of the complexity of the life cycle and of the fact that condensed chromosomes have not been demonstrated at any stage.

Electron microscopy, however, has revealed the presence of 14 kinetochores in $P$. falciparum which

\footnotetext{
* Laboratory for Protozoology, Institute of Tropical Medicine, 155 Nationalestraat, B-2000 Antwerpen.

** Vrije Universiteit Brussel, Paardenstraat, St. Genesius Rode. Correspondence address : Ahamada Said, Institute of Tropical Medicine, 155 Nationalestraat, B-2000 Antwerpen, Belgique.
}

Résumé : PlaSMODIUMS DE RONGEURS : CARACTÉRISATION DES ESPECES, SOUS-ESPECES ET LIGNÉES PAR CARYOTYPAGE MOLÉCULAIRE. Le caryotype moléculaire des plasmodiums de rongeurs P. berghei 13 souches, 2 lignées), P. yoelii (2 souches), P. chabaudi (3 souches, 1 lignée) et $P$. vinckei (4 souches) a été étudié par électrophorèse en gel à champs orthogonaux alternés (OFAGE). Le génome de chaque espèce a été résolu en 9 à 11 bandes supposées représenter 14 chromosomes dont la taille varie de 600 à 3500 kilobases. Après migration, la position de certains chromosomes a permis l'identification d'un caryotype original pour chaque souche étudiée. P. yoelii apparaît très différent des trois autres espèces par la taille et le nombre des chromosomes ainsi que l'affectation des sondes d'ADN. La localisation chromosomique des 5 sondes choisies a permis l'identification des chromosomes homologues dans les différentes espèces et souches. La localisation du gène "PMMSA" de P.c. chabaudi IP-PC 1 permet la distinction des quatre espèces de plasmodiums de rongeurs. Le caryotype moléculaire combiné à la localisation des sondes sur certains chromosomes fournit un outil précieux pour une caractérisation plus fine des parasites du paludisme.

MOTS CLES : Plasmodiums de rongeurs. espèce. souche. lignée. clone. caryotype. électrophorèse à champs alternés. sondes ADN.

ABREVIATIONS : PMMSA, précurseur de l'antigène majeur de la surface des mérozoiltes; OFAGE, électrophorèse en gel à champs orthogonaux alternés PFGE, électrophorèse à champs pulsés.

were considered as the haploid chromosomes number (Prensier \& Slomianny, 1986). To date there have been few DNA markers which would be useful for a more precise genetic definition of lines used in malaria research projects. A new tool to study the genomic organisation has been provided by the technique of pulsed-field gradient gel (PFG) electrophoresis (Schwartz et al., 1983) which allows the separation of DNA molecules within the 30 to 3.000 kilobases range. Using PFG many studies have been carried out on the chromosomes number of plasmodia. These studies have shown that the chromosomes are highly polymorphic in size and that the number of chromosomes seems to be 14 (Kemp et al., 1985 ; Sharkey et al., 1988 ; Janse et al., 1989 ; Ponzi et al., 1990). Laboratories where several species or subspecies of rodent malaria parasites are simultaneously in use for different research studies need specific markers for detecting mixed infections. In the present study this technique was applied to the molecular karyotype chracterization of rodent malaria parasites. Five DNA markers (2 chromosomes-specific probes, 2 cDNA clones and one genomic DNA marker) were located. 


\section{MATERIALS AND METHODS}

\section{CHARACTERIZATION OF PARASITES}

Strains, lines and clones in this work were defined as follows :

- A strain is a sample of parasites collected from a naturally infected host on a single occasion ;

- Lines are parasites which have undergone particular passage series in the laboratory ;

- A clone (opposed to population) is composed of genetically identical organisms derived from a single cell by asexual division.

Before analyse, all strains and lines were maintained for a while in white mice from cryopreserved stabilates ;

- P. berghei $\mathrm{K} 173 \mathrm{R}$ line is resistant to chloroquine ;

- All parasites are populations except 8417, 8495 and IP-PCI which are clones.

\section{DNA PREPARATION}

Parasites were prepared for electrophoresis as described by Kemp et al. (1985). Parasitised red blood cells were collected from mice and leucocytes removed by passage through a CF11 cellulose powder column. After saponin $(0.02 \%)$ hemolysis the parasites were washed twice in phosphate buffered saline (PBS) at $10.000 \mathrm{tr} / \mathrm{mn}$ for $1 \mathrm{mn}$.

The pellet was resuspended in PBS to an approximate concentration of $3.10^{8}$ parasites per $\mathrm{ml}$ and added to an equal volume of $2 \%$ low-melting point agarose at $37^{\circ} \mathrm{C}$. The blocks were incubated at $42^{\circ} \mathrm{C}$ for $48 \mathrm{~h}$. in $0.5 \mathrm{M}$ EDTA/0.01 M TRIS/ $1 \%$ sarkosyl $/ 2 \mathrm{mg}$ $\mathrm{ml}^{-1}$ proteinase $\mathrm{K}$.

The blocks were then stored in the same solution at $4^{\circ} \mathrm{C}$.

\section{Pulsed-FIELD GRADIENT GEL ELECTROPHORESIS}

The apparatus is a home-made modification of the Orthogonal Field Alternation Gel Electrophoresis
(OFAGE) set up and described by Schwartz et al. (1983). A third of each block was inserted into the slots of a $1 \%$ agarose gel in $0.5 \mathrm{x}$ Tris/Borate/EDTA (TBE) buffer and scaled into the slots with the same agarose gel. The pulse times used were 60,120 or 200 seconds depending on the DNA molecules size to be separated. The gel electrophoresis was run at $270 \mathrm{~V}$ for 20 hours at $14^{\circ} \mathrm{C}$.

After running, the gel was stained in $0.5 \mathrm{x}$ TBE containing ethidium bromide $(1 \mathrm{mg} / \mathrm{ml})$ for $30 \mathrm{~min}$ and photographied under an UV transluminator with a polaroid film (type 55 or 57 ).

\section{DNA PROBES}

Probes $5(5 \mathrm{~Kb})$ and $7(3,5 \mathrm{~Kb})$ are genomic DNA clones from $P$. berghei Anka 8417 which are specific for chromosomes 5 and 7 respectively.

Clones $\mathrm{W}$ and $\mathrm{Y}$ and $\mathrm{X}$ are cDNA clones from $P$. chabaudi IP-PC1 and correspond to the following expressed proteins :

$\mathrm{W}$ is a cDNA clone ( $\left.\mathrm{n}^{\circ} 100\right)$ of $2.4 \mathrm{~kb}$ corresponding to the central part of the $P$. chabaudi PMMSA (Deleersnijder et al., 1990);

$\mathrm{Y}$ is a cDNA clone $\left(\mathrm{n}^{\circ} 110\right)$ of $1.1 \mathrm{~kb}$ corresponding to a schizont-specific protein ;

$\mathrm{X}$ is a genomic DNA clone (X2A) of $2.3 \mathrm{~kb}$ corresponding to a part of a phosphoprotein associated with the erythrocyte cell membrane (Deleersnijder et al., 1992).

\section{SOUTHERN TRANSFER AND HYBRIDIZATION}

Agarose gels were southern-blotted to Hybond-N membranes (Amersham). DNA probes were radiolabelled by means of multiprime DNA labelling system (Amersham). Hybridization was performed under standard conditions at $65^{\circ} \mathrm{C}$. After hybridization the blots were washed at low stringency in 6x SSC for 10 min at room temperature followed by an another wash in $2 \mathrm{x} \mathrm{SSc} / 0.1 \% \mathrm{SDS}$ at $65^{\circ} \mathrm{C}$ for $30 \mathrm{~min}$.

Autoradiography was performed using an intensifying screen with Fuji RX X-ray film.

\begin{tabular}{|c|c|c|c|}
\hline P. berghei & P. yoelii & P. chabaudi & P. vinckei \\
\hline $\begin{array}{l}P \text {. berghei } \\
\text { Anka } 8417\end{array}$ & P. yoelii $17 \mathrm{X}$ & P. c. chabaudi $54 \mathrm{X}$ & P.v. vinckei 67 \\
\hline $\begin{array}{c}\text { P. berghei } \\
\text { Anka } 8495 \text { (line) }\end{array}$ & P.y. killicki & $\begin{array}{c}\text { P.c. chabaudi } \\
\text { 54X IP-PC1 (line) }\end{array}$ & P.v. bruce chwatti \\
\hline $\begin{array}{c}\text { P. berghei K } 173 \\
\text { P. berghei } \\
\text { K173R (line) } \\
\text { P. berghei } \mathrm{SP} 11\end{array}$ & & $\begin{array}{l}\text { P. c. chabaudi } \mathrm{CB} \\
\text { P. c. chabaudi } \mathrm{AS}\end{array}$ & P.v. lentum \\
\hline
\end{tabular}




\section{RESULTS}

P

FG gel electrophoresis was applied on three strains of $P$. berghei, two strains of P.yoelit, three strains of $P$. chabaudi, three strains of $P$. vinckei, two lines of $\mathrm{P}$. berghei and one line of $P$. chabaudi. Different pulse times were used to achieve the separation of small or large chromosomes (results not shown). The karyotype of the $P$. berghei clone Anka 8417 was chosen as reference for chromosomes number because it can undergo the full life cycle and therefore is unlikely to lack essential genetic information (Ahamada Saïd et al., 1986).

The results show in $P$. berghei and $P$. chabaudi up to eleven well distinguishable chromosome bands and ten in P. vinckei. Apparently this restricted resolution is so far the best approach to the basic number of 14 chromosomes (Janse et al., 1989 ; Sharkey et al., 1988 ; Sheppard et al., 1989). In our experiments, chromosomes 9 to 12 appear as a non resolved entity. On the other hand, the two strains of $P$. yoelii differ considerably and show only 6 or 7 intense chromosomal bands.

\section{MOLECULAR KARYOTYPE}

\section{P. berghei}

The number of chromosomes within each isolate is very similar but their size may be different. Some chromosomes comigrate in the gel : Chromosomes 12 in the K173 strain, K173R line and SP11 strain ; chromosomes 2-3 in the SP11 strain ; chromosomes 5-6 in the K173R line ; chromosomes 5-6-7 in the 8495 line ; chromosomes 9-10-11 in all strains.

The position of certain chromosomes allows an easy identification of each strain and line : chromosomes 1 , 2, 3 and 4 of K173 strain are smaller than in the other strains and lines; chromosome 7 of the K173 and SP11 strains is smaller than the homologous chromosomes of the Anka strain ; chromosome 7 of Anka 8417 is larger than the homologous chromosome in the Anka line 8495 ; chromosome 9 of the Anka strain is larger than the homologous chromosome in the other strains and migrates together with the non resolved chromosomes ; in clone 8417 the straining intensity of chromosome 7 with ethidium bromide decreased significantly after numerous mechanical passages as shown in fig. $2 \mathrm{~A}$ (passage $\mathrm{n}^{\circ} 63$ ).

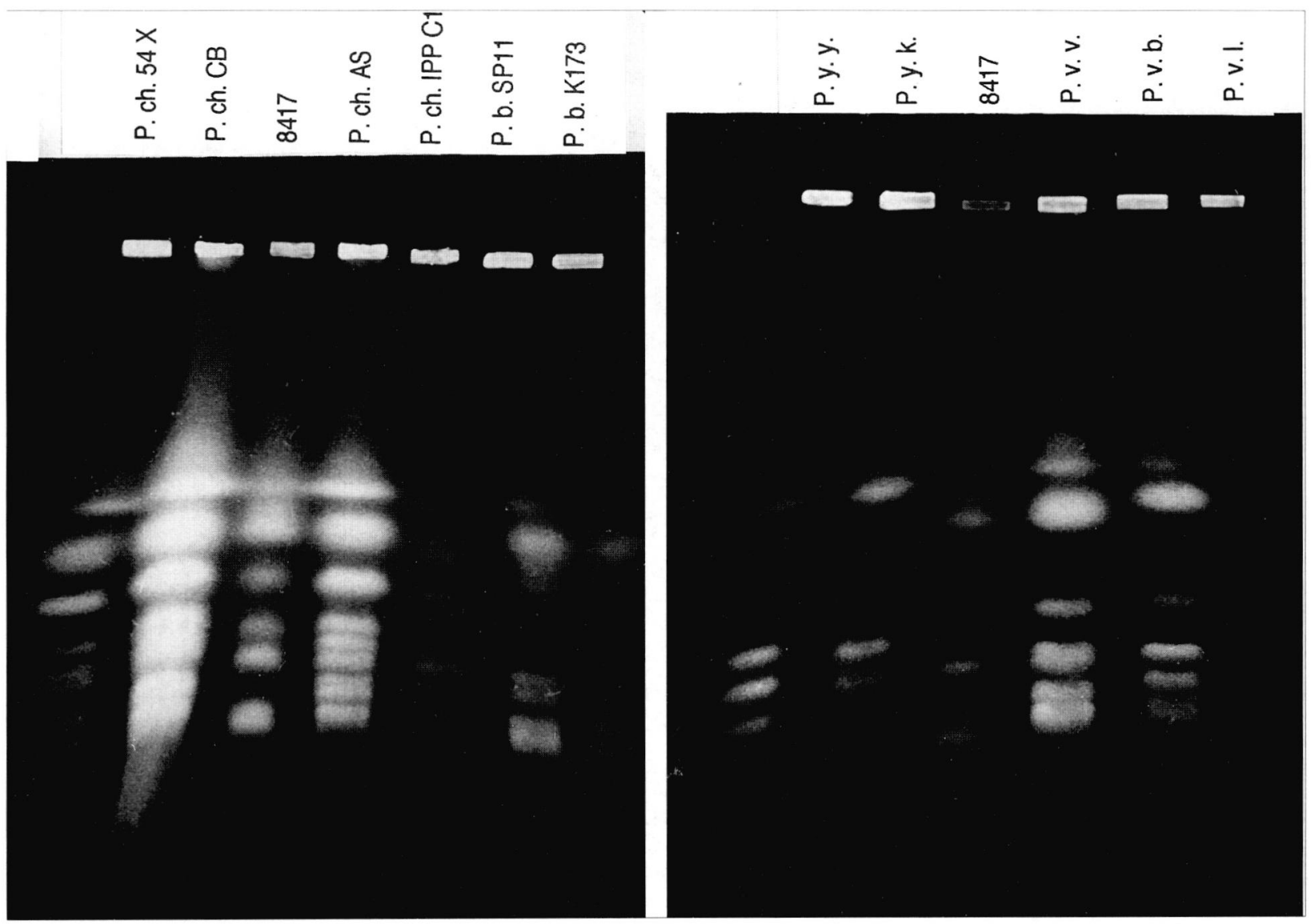

Fig. 1

Karyotypes of different populations of rodent malaria parasites separated by pulsed field gel electrophoresis. OFAGE was performed in a standard home made electrophoresis chamber at $270 \mathrm{~V}$, with lineary increasing pulse times from 60 to 200s. Run time was 20 hours at $14^{\circ} \mathrm{C}$. 


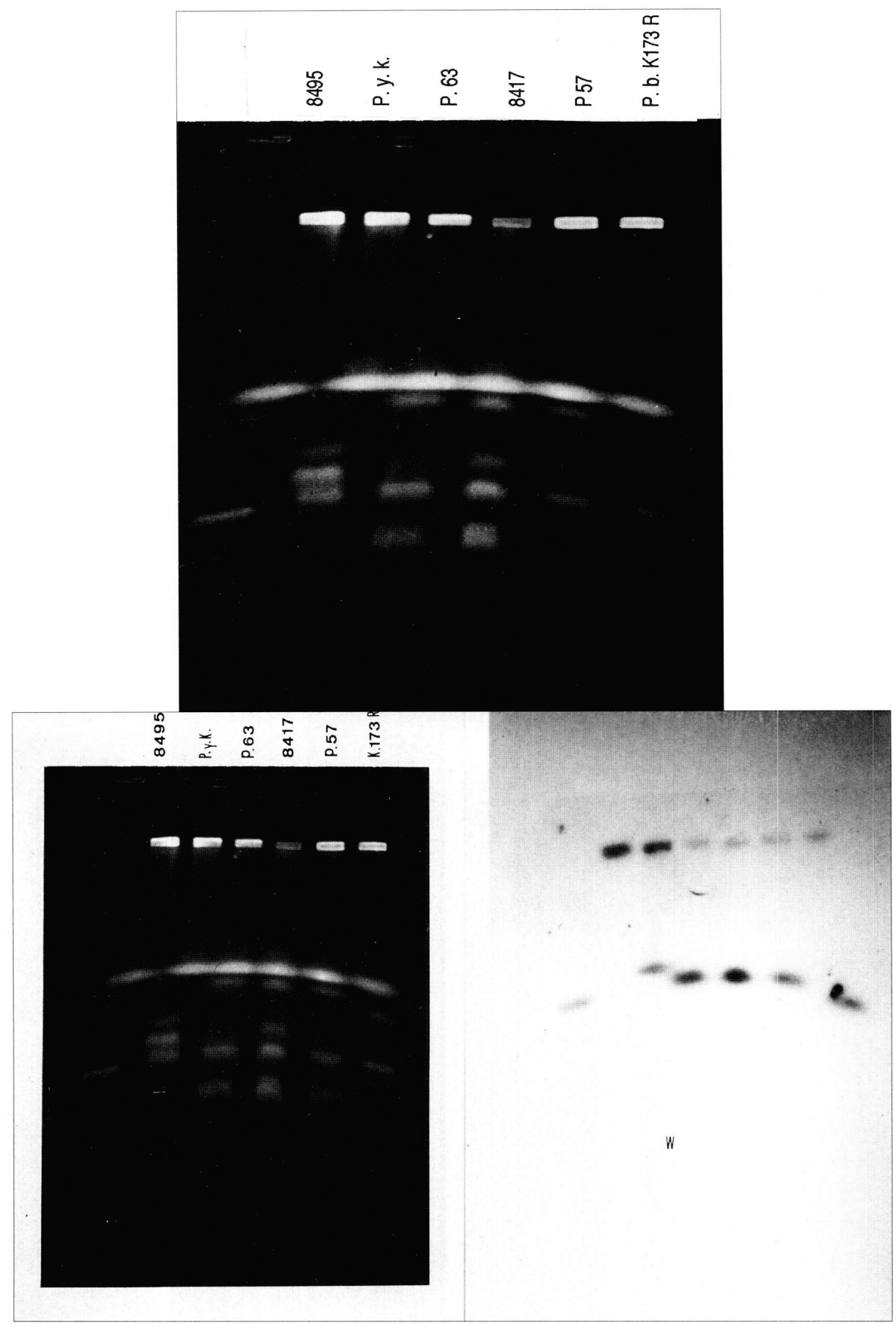

Fig. 2.

A. Karyotypes of different populations of rodent malaria parasites separated by PFG. OFAGE was performed in a standard home made chamber at $270 \mathrm{~V}$ with lineary increasing forward pulse times from 60 to $100 \mathrm{~s}$, run time was 20 hours at $14^{\circ} \mathrm{C}$. B. Ethidium bromide staining of OFAGE separated chromosomes and Southern blot of the same gel hybridized to probe W. 

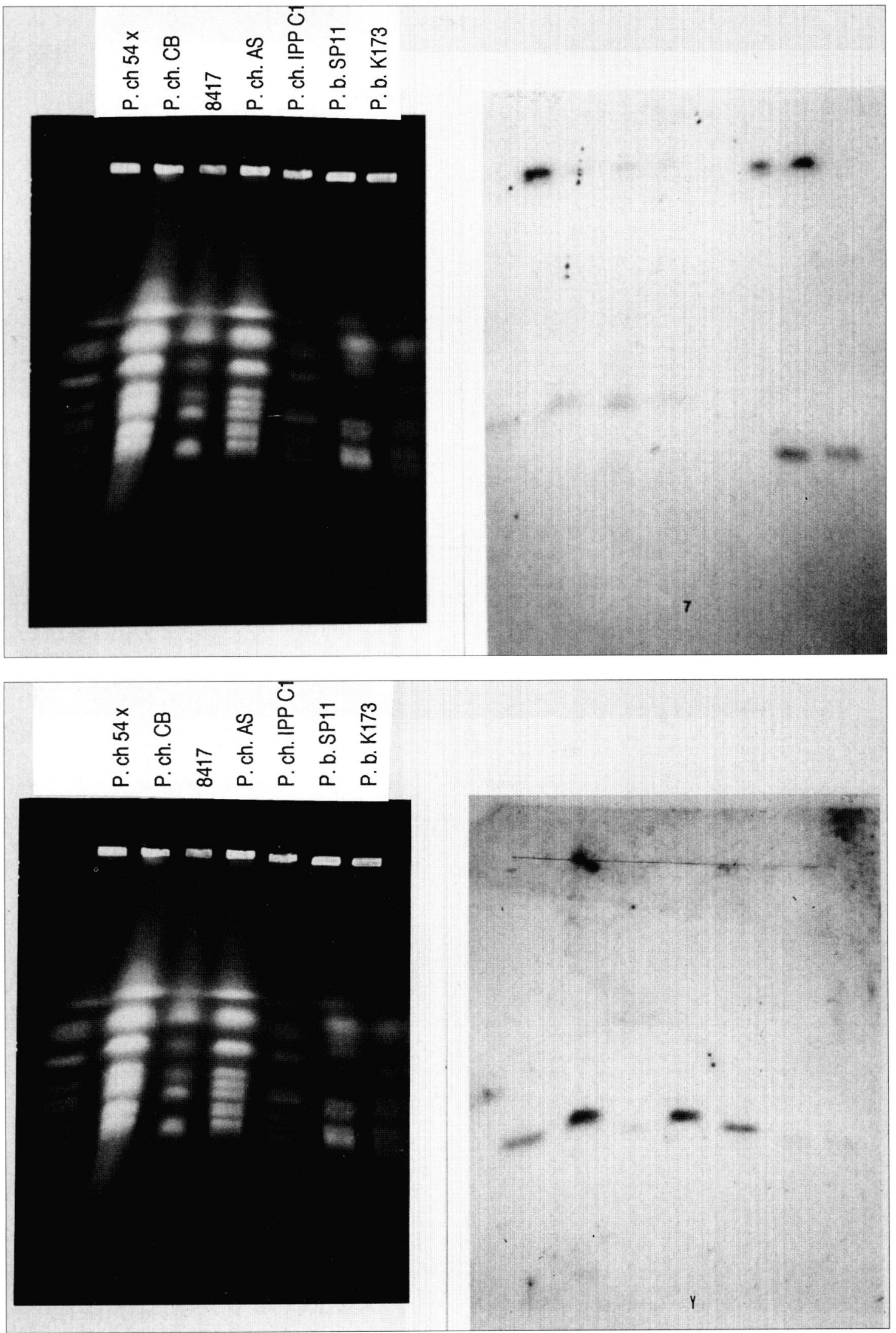

Fig. 3.

Ethidium bromide staining of OFAGE

separated chromosome and Southern blot of the same gel hybridized to probe 7 and probe $\mathrm{Y}$. 


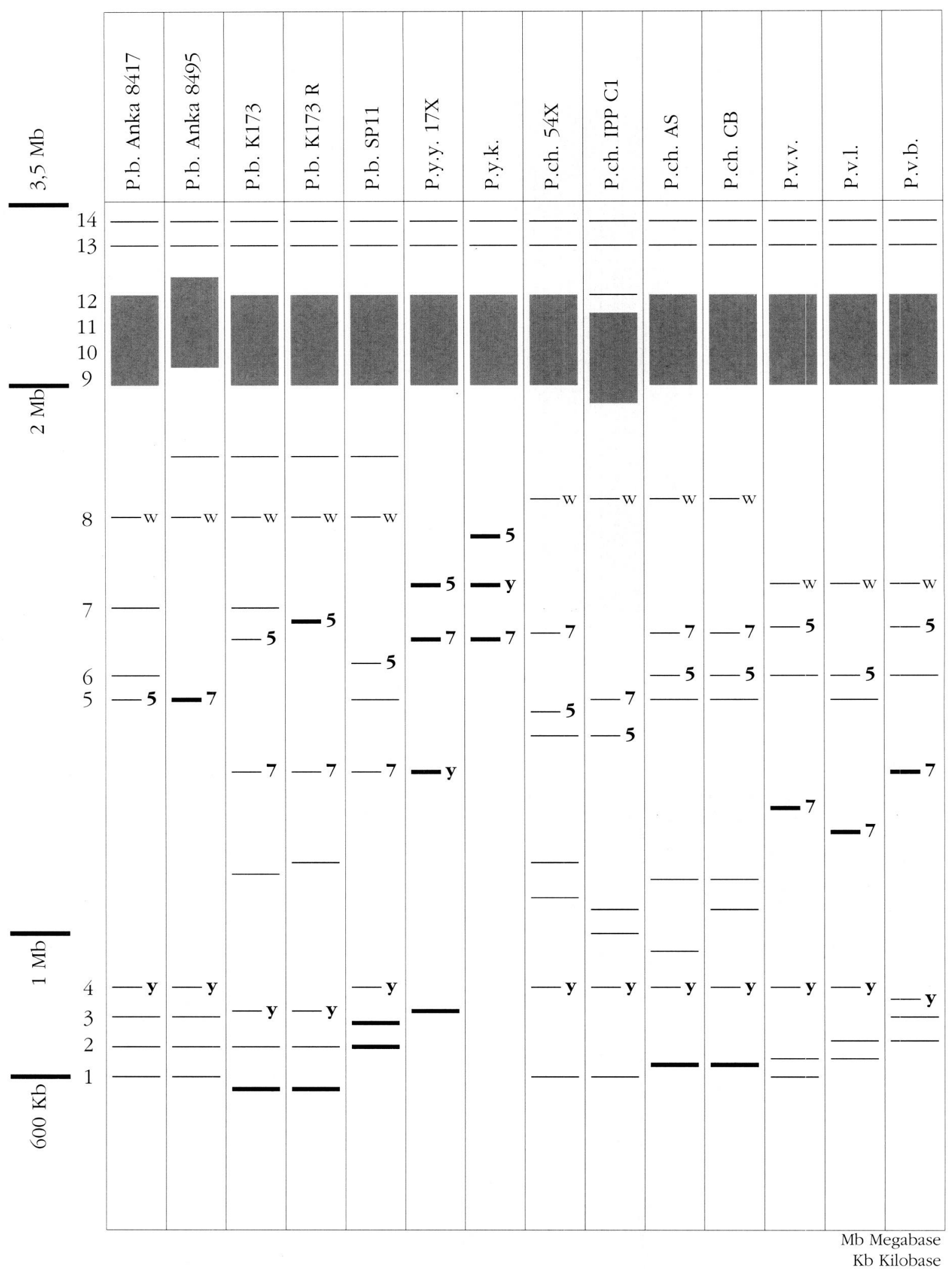

Tableau I. - Karyograms of rodent malaria parasites examined in this study. $P$. berghei Anka 8417 was taken as reference karyotype and the chromosomes were numbered consecutively from smallest to largest. Mapping of cDNA clones (W - Y) and genomic DNA clones ( 7 - 5 and $\mathrm{X}$ ) to chromosomes of parasites under study. 


\section{P. yoelii}

Most of the chromosomes of two P. yoelii strains comigrate and each strain shows an unique pattern which allow to differentiate them from the other strains and lines under study.

\section{P. chabaudi}

Each of the four $P$. chabaudi examined exhibited a different chromosome migration pattern. A number of chromosomes comigrate as was previously observed in P.c. adami and P.c. chabaudi CB (Sheppard et al., 1989).

\section{P. vinckei}

The karyotypes of the three $P$. vinckei strains are different. The position of chromosomes 5, 6 and 7 permit to discriminate them. Chromosomes 1-2, 3-4 and 10-11-12 comigrate.

\section{ASSIGNMENT OF DNA SEQUENCES}

\section{TO SPECIFIC CHROMOSOMES}

Three DNA probes from $P$. chabaudi were mapped to chromosomes by Southern hybridization in PFG blot : probe $\mathrm{X}$ recognises comigrating chromosome bands (10-11 and 12) in all the isolates, the two others probes ( $\mathrm{T}$ and $\mathrm{W}$ ) hybridize to single chromosome band indicating that they could be used as chromosomes specific markers for rodent malaria parasites. In $P$. yoelii the probe $\mathrm{W}$ recognizes the same comigrating chromosomes as probe Y (10-1112). Two specific markers respectively for chromosomes 5 and 7 isolated from a genomic library of $P$. berghei Anka (Ponzi et al., 1990) were used to identify chromosomes sharing homologous genetic information in the different isolates and lines used in this study. Each probe hybridized to single chromosome band of different molecular weight. The results of chromosome specific hybridization of all the probes are summarized in table I. The three probes coding for expressed proteins localise chromosomes of similar size in $P$. berghei, $P$. chabaudi and $P$. vinckei.

\section{DISCUSSION}

1 he molecular karyotype of the four species of rodent malaria parasites have been characterized by PFG. It must be born in mind that for total populations the karyotype is clearly different after cyclical transmission and unstable after mechanical passage (Ahamada Said, 1987). These observations suggest that total populations are composed of a mixture of parasites with different karyotypes. $P$. yoelii appears to differ considerably from the three other rodent malaria species by karyotype and gene localisation.

\section{Number AND POSITIONS OF THE BANDS}

Consistent with reported studies of rodent malaria karyotype (Sheppard et al., 1989 ; Sharkey et al., 1988 ; Langsley et al., 1987 and Janse et al., 1989) ; the present analysis shows an important karyotype polymorphism within and between species, strains and lines. Each cloned parasite exhibits an unique karyotype pattern which remains stable after mechanical or cyclical passages (Ahamada Saïd, 1987). However, continuous mechanical passages seemed to exert a selective pressure in favour of particular karyotype mutants. Such conditions take place only in laboratory and are thus easy to control. A decreasing intensity of chromosome 7 and the loss of gametocyte infectivity occured simultaneously after 58 and 63 mechanical passages of the clone 8417. However there is no direct correlation between karyotype and gametocyte infectivity. This decreasing intensity of chromosome 7 can be explained by a variation in the number of copies of a subtelomeric repetitive element $(2.3 \mathrm{~Kb})$ which seemed to be involved in the chromosome size polymorphism (Ponzi et al., 1990).

Molecular karyotype techniques were able to differentiate three $P$. berghei isolates showing identical isoenzyme or morphological patterns.

\section{THE USE OF PROBES}

Strains and lines of the four rodent malaria species were identified for the first time by chromosome specific and DNA probes recognizing homologous chromosomes or chromosomes sharing the same genetic information. The three $P$. chabaudi probes and the two $P$. berghei chromosome specific probes all hybridized to the four rodent plasmodia species.

Probes 5 and 7 showed marked chromosomal location differences in all species, lines and strains indicating that they can be used as specific markers for all the rodent malaria parasites. The probe $\mathrm{W}$ which represents the PMMSA is localised on chromosomes of slightly different size in the four species. Moreover, within each species, very little size variation is observed and probe $W$ is therefore a useful species differentiator key after isoenzymes.

The other genes (X, Y), corresponding to expressed proteins, are also located in $P$. chabaudi, $P$. berghei and $P$. vinckei on chromosomes showing relative size conservation. This could be the effect of close phylogenetic relation. $P$. yoelii seems to differ from the other three rodent malaria species by chromosome size, lack of small chromosomes and localisation of probes. Based upon the analysis of the small subunit ribosomal RNA sequences, $P$. berghei seemed to be phylogenetically closer to $P$. vinckei than to $P$. yoetii 
(Waters et al., 1991). This suggests that P. yoelii is phylogenetically not as closely related as the other three and should not be grouped with $P$. berghei as is usually done. A molecular tree made with chromosomal assignment of DNA probes also showed that $P$. berghei is closer to P. vinckei than to P. yoelii (results not shown).

Molecular karyotype combined to assignment of DNA probes ( $15,7, \mathrm{~W}$ and $\mathrm{Y}$ ) provide an unambiguous characterization and a more precise genetic definition of parasites lines and isolates used in immunological and genetic research. These markers can be used for detection of accidentally cross contamination arising by manipulating different species or subspecies of rodent malaria involved in different areas of research. The probes can also be used as genetic markers in crossing experiments and as valuable tools at taxonomic level.

\section{ACKNOWLEDGEMENTS}

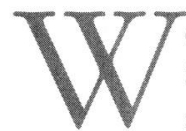
e thank Dr M. Ponzi (Istituto Superiore di Sanita, Rome) for providing the probes 5 and 7 and Dr W. De Leersnijder (Vrije Universiteit, Brussels) for providing the probes $\mathrm{W}, \mathrm{X}$ and $\mathrm{Y}$.

This work was supported by EEC contract TSD-M-052.

\section{REFERENCES}

AHAMADA SAID : Observations sur l'infectivité des gaméto cytes de $P$. berghei Anka et sur son déterminisme géné tique. Ph. D thesis, Vrije Universiteit Brussel, 1987.

Ahamada Said, Timperman G. \& Wéry M. : Influence de la maintenance d'une souche de Plasmodium berghei Anka sur la gamétogénèse. Ann. Soc. belge Méd. Trop., 1986, 66, 123-131.

CARTER R. : Enzyme variation in Plasmodium berghei and Plasmodium vinckei. Parasitol., 1973, 66, 297-307.

Deleersnijder W., Hendrix D., Bendahman N., Hanegreefs J., Brys L., Hamers-Casterman C. and Hamers R. : Molecular cloning and sequence analysis of the gene encoding the major surface antigen of P. chabaudi chabaudi IP-PCI. Mol. and Biochem. Parasitol., 1990, 43, 232-244.

Deleersnijder W., Prasomsitti P., Tungpradubkul S., Hendrix D., Hamers-Casterman C. and Hamers R. : Structure of $P$. chabaudi acidic phosphoprotein that is associated with the host erythrocyte membrane. Mol. and Biochem. Parasitol., 1992, 56, 59-68.

Janse C.J., Boorsma E.G., Ramesar J., Van Vianen Ph., Van der Meer R., Zenobi P., Casaglia O., Mons B. and Van der Berg F.M. : Plasmodium berghei : Gametocyte production, DNA content, and chromosome-size polymorphisms during asexual multiplication in vivo. Exptl parasit., 1989, 68, 274282
Kemp D.J., Corcoran L.M., Coppel R.L., Stahl H.D., Blanco A.E., Brown G.V. and ANDers R.F. : Size variation in chro mosomes from independent cultured isolates of Plasmodium falciparum. Nature, 1985, 315, 347-350.

Langsley G., Sibilli L., Mattei D. Falanga P. and MercereauPujAlON O. : Karyotype comparison between Plasmodium chabaudi and Plasmodium falciparum : Analysis of a Plasmodium chabaudi cDNA containing sequences highly repetitive in Plasmodium falciparum. Nucleic Acids Research, 1987, 15, 2203-2211.

Ponzi M., Janse C.J., Dore E., Scotti R., Pace T., Reterink T.J.F., VAN DER Berg F.M. and Mons B. : Generation of chromo some size polymorphism during in vivo mitotic multiplica tion of Plasmodium. Mol. Biochem. Parasitol. 1990, 41, 7382.

Prensier G. and Slomianny Ch. : The karyotype of Plasmodium falciparum determined by ultrastructural serial sectioning and 3D reconstruction. Journal of Parasitology, 1986, 72, 731-736.

Schwartz D.C., Safran W., Welsh J., HaAs R., Goldenberg M. and CANTOR C.R. : New techniques for purifying large DNAs and studying their properties and packaging. Cold Spring Harbor Symposium of Quantitative Biology, 1983, 47, 189195.

Sharkey A., Langsley G., Paratarapotikul J., Mercereau-Pujalon O., MC LEAN A.P. and WALLIKER D. : Chromosome size varia tion in malaria parasite of rodents, Plasmodium chabaudi. Molecular and Biochemical Parasitology, 1988, 28, 47-54.

Sheppard M., Thompson J.K., Anders R.F., Kemp D.J. and Lew A.M. : Molecular karyotyping of the rodent malarias Plasmodium chabaudi, Plasmodium berghei and Plasmodium vinckei. Mol. Biochem. Parasitol., 1989, 34, 4552.

Walliker D., Quaky I.A., Wellems T.E., Mc Cutchan T.F., Szarfman A., London W.T., Corcoran L.M., Burkot T.M. and CARTER R. : Genetic analysis of the human malaria parasite Plasmodium falciparum. Science, 1987, 236, 1661-1666.

Waters A.P., Higgins D.G. and Mc Cutchan T.F. : P. falcipa rum appears to have arisen as a result of lateral transfer between avian and human hosts. Prc. Natl Acad. Sci., USA, 1991, 88, 3140-3144.

Accepté le 22 novembre 1993 